\title{
Informação mediada como instrumento de transformação social
}

\author{
Rosiane da Silva Costa \\ Universidade Federal do Ceará, Departamento de Ciências da Informação, Fortaleza, CE, Brasil \\ e-mailrosianescf@gmail.com \\ Maria Giovanna Guedes Farias \\ Universidade Federal do Ceará, Departamento de Ciências da Informação, Fortaleza, CE, Brasil \\ mgiovannaguedes@gmail.com
}

DOI: https://doi.org/10.26512/rici.v12.n2.2019.8873

Recebido/Recibido/Received: 2018-06-11

Aceitado/Aceptado/Accepted: 2018-12-26

Resumo: Apresenta-se resultado de pesquisa que objetivou analisar as estratégias de mediação da informação utilizadas pelos profissionais que trabalham na Biblioteca Pública Municipal Capistrano de Abreu, situada na cidade de Maranguape, Ceará, Brasil, a fim de compreender o exercício da prática mediadora e da informação como instrumento de transformação social. Utiliza-se quanto ao percurso metodológico a abordagem qualitativa e o método de pesquisa exploratória. Os dados foram coletados por meio de entrevista e da aplicação de questionários, sendo analisados pela técnica de análise de conteúdo de Bardin, com o estabelecimento de categorias. Os resultados demonstram as estratégias de aproximação e mediação ocorrem por meio da interação estabelecida entre usuários, profissionais e biblioteca, quando os usuários são motivados a participar do planejamento dos serviços oferecidos. Conclui-se que, a biblioteca deve manter o foco em planejar e realizar ações de mediação que favoreçam a apropriação da informação por meio de intervenções sociais, como ações culturais, mediações orais e de leitura, oficinas entre outros, abrindo as portas para a comunidade, posicionandose e mobilizando-se frente à sociedade, à medida que presta serviços de informação para a população local. Esses eventos tendem a instigar a participação coletiva, onde experiências são compartilhadas e conhecimentos são construídos.

Palavras-chave: ações de mediação. biblioteca pública. Biblioteca Pública Municipal Capistrano de Abreu. mediação da informação.

\section{Information mediated as an instrument of social transformation}

Abstract: We present a research result that aimed to analyze the information mediation strategies used by professionals working in the Municipal Public Library Capistrano de Abreu, located in the city of Maranguape, Ceará, Brazil, in order to understand the practice of mediating practice and information as an instrument of social transformation. The qualitative approach and the method of exploratory research are used in the methodological course. Data were collected through interviews and questionnaires, and analyzed by the Bardin content analysis technique, with the establishment of 
categories. The results demonstrate the strategies of approximation and mediation occurring through the established interaction between users, professionals and library, when the users are motivated to participate in the planning of the services offered. It is concluded that the library should focus on planning and carrying out mediation actions that favor the appropriation of information through social interventions, such as cultural actions, oral and reading mediations, workshops among others, opening the doors to the community, positioning itself and mobilizing in front of society, as it provides information services to the local population. These events tend to instigate collective participation, where experiences are shared, and knowledge is built.

Keywords: information mediation. mediation actions. Municipal Public Library Capistrano de Abreu. public library.

\section{Información mediada como instrumento de transformación social}

Resumen: Se presenta un resultado de investigación que objetivó analizar las estrategias de mediación de la información utilizadas por los profesionales que trabajan en la Biblioteca Pública Municipal Capistrano de Abreu, situada en la ciudad de Maranguape, Ceará, Brasil, a fin de comprender el ejercicio de la práctica mediadora y de la información como instrumento de transformación social. Se utiliza en cuanto al recorrido metodológico el abordaje cualitativo y el método de investigación exploratoria. Los datos fueron recolectados por medio de entrevista y de la aplicación de cuestionarios, siendo analizados por la técnica de análisis de contenido de Bardin, con el establecimiento de categorías. Los resultados demuestran las estrategias de aproximación y mediación ocurren a través de la interacción establecida entre usuarios, profesionales y biblioteca, cuando los usuarios están motivados a participar en la planificación de los servicios ofrecidos. Se concluye que la biblioteca debe mantener el foco en planear y realizar acciones de mediación que favorezcan la apropiación de la información por medio de intervenciones sociales, como acciones culturales, mediaciones orales y de lectura, talleres entre otros, abriendo las puertas a la comunidad, posicionándose y movilizándose frente a la sociedad, a medida que presta servicios de información para la población local. Estos eventos tienden a instigar la participación colectiva, donde se comparten experiencias compartidas y los conocimientos se construyen.

Palabras clave: acciones de mediación. Biblioteca Pública. Biblioteca Pública Municipal Capistrano de Abreu. mediación de la información.

\section{Introdução}

Em meio às transformações ocorridas no cenário social, a informação se configura como um recurso de potencialização, tendo o homem, quando lhe é dado o direito ao acesso a esta, a oportunidade de utilizá-la e aplicá-la em prol do seu desenvolvimento social e intelectual. A construção do conhecimento por sua vez, não ocorre apenas com o acesso às informações, mas também por meio do compartilhamento de experiências e da interação estabelecida com ações individuais e coletivas no convívio social. A mediação da informação, processo que visa à construção de sentidos por meio da apropriação da informação, serviu de suporte teórico, conceitual e metodológico para esta pesquisa, uma vez que, entender este processo, é, sobretudo compreender o poder da informação na sociedade contemporânea.

Nas palavras de Carvalho (1991), os recursos interativos da comunicação e o acesso à informação se reestruturaram na sociedade, e as discussões empreendidas acerca do acesso à informação como sendo um direito do cidadão ganharam significação. Entendemos que a 
informação seja um forte instrumento para inclusão do homem nos sistemas que movem as relações sociais, e que ela pode potencializar o exercício da cidadania.

Nesta perspectiva, chamamos atenção para uma reflexão acerca do poder da informação e as estratégias usadas para sua disseminação nas bibliotecas públicas (BP), especialmente na Biblioteca Pública Municipal Capistrano de Abreu (BPMCA), localizada no centro da cidade de Maranguape, região metropolitana de Fortaleza, campo de pesquisa escolhido para este estudo. Neste ponto, destacamos a importância das unidades de informação (bibliotecas, arquivos, museus, centros de documentação e etc.), como meios de compartilhamento de informações e oferta de serviços informacionais, tendo assim papel fundamental no que diz respeito à circulação de informação. (CARVALHO, 1991).

Contudo, é relevante ressaltar, que a mediação da informação tratada nesta pesquisa, vai muito além da aplicação de seus conceitos relacionados apenas aos processos de disseminação de informação. A mediação aqui abordada está centrada nos princípios que visam à interferência e à apropriação da informação, vinculadas à construção de consciência. Posto isso, abordamos o espaço da biblioteca pública como veículo de promoção de conhecimentos, uma vez que sendo esta uma instituição social, precisa mobilizar-se para atuar como equipamento informacional de responsabilidade social, e seus profissionais devem desenvolver competências e habilidades para exercerem o papel de profissionais mediadores e agentes públicos.

Trabalhar nesta perspectiva de mediador exige do bibliotecário a consciência, de que ele pode e deve atuar como agente educador e transformador, criando um vínculo entre a unidade e o usuário. Por isso, notamos que o ato de mediar à informação necessita do desenvolvimento do lado mais humano dos profissionais, "[...] e o entendimento de que ele é o principal protagonista de todas as ações de informação [...]" em qualquer ambiente e contexto. (FARIAS, 2014, p. 17). Mediar a informação não é apenas oferecer acesso, mas também interagir com os usuários para melhor entender seus anseios e necessidades.

A mediação da informação se caracteriza como um ciclo, onde a informação mediada ao mesmo tempo em que responde questionamentos gera novas incertezas. Sabemos que a mediação da informação pode ocorrer em qualquer espaço, mas destacamos aqui o espaço das bibliotecas e unidades de informação como adequados meios interativos de disseminação. As bibliotecas, de modo geral, têm em sua essência a obrigação de manter vínculos com a comunidade e abrir espaços de diálogo.

No âmbito das bibliotecas públicas, especificadamente da Biblioteca Pública Municipal Capistrano de Abreu, as oportunidades e necessidades de implementação de ações de mediação da informação podem acontecer por meio de diversos recursos interativos ou de 
mediações culturais. Assim, corroboramos com os pensamentos de Sanches e Rio (2010), que ressaltam a relevância da mediação da informação no fazer bibliotecário, ao esclarecer que é imprescindível o compromisso e a responsabilidade deste profissional como agente participativo no processo de construção do conhecimento de seus usuários, porém ele deve acima de tudo conhecer esses usuários e se reconhecer como parte deles. Conhecer o usuário implica em conhecer suas necessidades informacionais, a fim de oferecer a estes o recurso necessário para seu desenvolvimento intelectual e social.

\section{Mediação da informação: um conceito interdisciplinar}

Para que a prática da mediação da informação seja compreendida, optamos por abordar o assunto em sua forma interdisciplinar, destacando os diversos conceitos em torno do termo mediação, bem como sua abrangência em algumas áreas do conhecimento. Para tal, nos aportamos nas palavras de Bortolin e Santos Neto $(2015$, p. 37$)$ que afirmam que:

Com as leituras e as pesquisas realizadas no referido grupo, identificamos que o termo mediação é utilizado tanto na fala dos profissionais quanto no discurso expressos nas publicações dos pesquisadores em diversas áreas do conhecimento. No âmbito do direito existem os mediadores de conflitos, da pedagogia os mediadores pedagógicos e no serviço social os mediadores sociais etc. e assim por diante.

Portanto, para analisar a dinâmica da interdisciplinaridade da mediação da informação, entendemos que é preciso, primeiramente, apresentar alguns conceitos da mediação utilizados no Direito, na Educação, Comunicação Social e por fim na Ciência da Informação. Seguimos esse percurso conceitual, pois ainda segundo Bortolin e Santos Neto (2015), as pesquisas sobre mediação, em seus mais diversos segmentos, têm adquirido cada vez mais relevância, tendo em vista a importância em aperfeiçoar as formas de trabalho com a informação no atual contexto social. Entendemos assim, que cada área tem seu respectivo estudo, adquirindo a mediação em múltiplos significados. Para iniciamos esse percurso conceitual em torno da mediação nas áreas acima apresentadas, nos aportamos nas reflexões de Davallon (2003, p. 7):

Vários setores de investigação utilizam a noção de mediação como conceito operatório para designar, descrever ou analisar um processo específico. Daí a presença de propostas de definição, que parecem, contudo, variar consideravelmente de um setor para outro.

O termo mediação se origina do latim, tendo entre seus inúmeros significados a intervenção entre duas partes numa situação de conflito. Mediar, portanto, é "[...] qualquer processo no qual, dois elementos são colocados em articulação através da intervenção de um terceiro." (SANTAELLA; NÖTH, 2004, p. 202). Neste sentido, entendemos a mediação como 
uma ação facilitada pela figura de um mediador, ou seja, um elo articularizador para interferir de maneira apropriada.

Destarte, apresentamos o conceito geral e dicionarizado da mediação, onde é entendida como um substantivo derivado de mediador, diretamente ligado a algo ou a aquele que intervém. Assim, nos reportamos automaticamente para o âmbito jurídico, onde a mediação é trabalhada em torno da resolução de conflitos e o mediador assume a posição de interferente, focado na solução de problemas de ambas as partes. Segundo Toaldo (2011), a mediação para resolução de conflitos, surge em meados dos anos 70 , como uma alternativa para resolver disputas onde as partes envolvidas não conseguem entrar em consenso. De tal modo:

\begin{abstract}
A mediação é definida como a interferência de um terceiro com poder de decisão limitado ou não autoritário, que ajudará as partes envolvidas a chegarem voluntariamente a um acordo, mutuamente aceitável com relação às questões de disputa. (TOALDO, 2011, online).
\end{abstract}

A autora ressalta que mais do que uma alternativa, a mediação exige uma integração de saberes, onde a interdisciplinaridade dos profissionais envolvidos fará toda a diferença. Vale ressaltar que o foco da medição no âmbito do direito é a restauração de relações, uma vez que promove a reaproximação entre as partes e os encoraja a encontrar a melhor forma de resolver seus impasses.

Na educação o termo mediação também se pauta na figura de um mediador, mas este não se apresenta como um facilitador para resolução de conflitos entre duas partes, mas como um sujeito ativo com quesito de orientação. Destarte as palavras de Marques (2006), ao ressaltar que é na mediação em sala de aula que se realizam as aprendizagens, compartilhando conhecimentos adquiridos na vida e os transformando em conteúdos, fazendo com que professores e alunos sejam atores de seu próprio ensino e aprendizado. Assim, corroboramos com Almeida (2007) ao definir mediação como conexões que se estabelecem entre as ações sociais e as formas de motivar essas ações, sejam estas de forma individual ou coletiva. Enquanto no jurídico o mediador busca um consenso na solução de um problema, onde não haverá ganhador nem perdedor entre partes, apresentando soluções cabíveis a ambos, na educação, este assumirá principalmente o papel de orientador, por meio de uma interação dialógica que conduza a uma aprendizagem.

Outro campo onde as práticas de mediação se fazem presente é o da comunicação social, porém acreditamos que antes de explanar algumas considerações sobre a mediação nesta área de estudo, precisamos expor alguns conceitos acerca do termo informação. Conforme Targino (1991, p. 155): 
[...] no contexto da teoria da informação, a informação é a redução da incerteza, quando se obtém resposta a uma formulação feita. A incerteza é a quantidade de respostas possíveis que conhecemos, apesar de não sabermos qual delas é a verdadeira.

Também baseado nos estudos da teoria da informação, Coelho Netto (2001) destaca que para se conceituar informação é preciso primeiramente se fazer uma distinção entre esta e o termo significação. Segundo o autor a significação é algo subjetivo que depende da interpretação dos sujeitos, podendo ser medido quantitativamente, enquanto a análise informacional indica relevância, pois será o diferencial para a redução de incertezas. Assim, entendemos a informação como a probabilidade de acertos, ou seja, quanto mais respostas de nossos questionamentos se obtêm, maior é a nossa capacidade de compreensão, reduzindo assim a nossa incapacidade de entendimento. A informação nada mais é do que a troca de conhecimento entre o sujeito e o mundo.

Quanto a relevância, ou o diferencial da informação, nos apropriamos das palavras de McGarry (1999), ao colocar a informação como uma escolha, o elemento surpresa que transforma nossa cognição, e que como consequência, nos informa a medida que aprendemos, corroborando com Coelho Netto ( 2001, p. 127), ao dizer que "[...] apenas o diferente interessa na informação".

De antemão, tudo o que precisamos entender sobre informação para começarmos nossas discussões sobre mediação no âmbito da comunicação, é que esta é uma ação que demanda uma reação, necessitando assim de um veículo condutor para sua transmissão. (MCGARRY, 1999).

Partindo para a perspectiva da mediação na comunicação, destacamos a ação diretamente interligada à mediatização, que conforme Cardoso (2007) se constitui como a saída da figura humana do mediador, para dar espaço aos sistemas de mídia, criando novos espaços de mediação e assumindo especificidades próprias neste processo. As mídias ou meios de comunicação em massa se constituem como os veículos condutores (mediadores) na transmissão de informação para a sociedade, na qual os processos de comunicação entre os sujeitos tornaram-se rápidos e imediatos. Assim entendemos a mediação na comunicação não como uma intermediação (presença de um intermediário), mas sim como uma desintermediação, processo visto por Silva e Lopes (2011), como um fenômeno gerado pela autonomia de usuários na busca pela informação.

Signates (1998) destaca a valor do conceito de mediação para a comunicação na contemporaneidade. Segundo o autor, de maneira mais restrita o significado de mediação liga- 
se diretamente a ideia do intermediário, porém as considerações acerca da mediação vão muito além.

Finalmente, partindo para o campo da Cl, temos as considerações de Busquet (2012), que tem a mediação como um processo de reflexão com ênfase na problematização do real, e o mediador como um agente pensante no processo de negociação dessas reflexões. Já Bortolin e Santos Neto (2015, p. 39), definem o mediador como "[...] aquele que se posiciona de maneira intencional e medeia algo ou alguma coisa para alguém, com o intuito de modificar a situação ou solucionar problemas", porém ressalta que esta não depende apenas do mediador, mas também da valorização e do reconhecimento do sujeito que a recebe, nos levando a entender o processo de mediação, como um processo social, tomando as palavras de Costa e Almeida Júnior (2012, p. 64), que afirmam que "a mediação passa por todos os processos de relação humana", onde o conhecimento é construído de forma recíproca e cabe ao mediador considerar todos os aspectos que envolvem essas relações. Almeida Júnior (2015) ressalta que as informações são dependentes das relações que fazemos com o meio externo, que por sua vez nos levam ao entendimento, mesmo que inconsciente, do mundo.

\subsection{Mediação da informação para conscientização}

A informação se configura como um instrumento de inclusão do homem nos sistemas que movem as relações sociais e o acesso a esta como o melhor caminho para que a inclusão social ocorra, potencializando o exercício da cidadania. Entender essa expectativa é acima de tudo compreender a importância do acesso à informação para a propagação de sujeitos conscientes e protagonistas de suas próprias vidas. Nesta perspectiva, abordamos a mediação da informação como um processo que busca suprir as necessidades informacionais dos sujeitos, entendendo que uma vez, atendida de forma satisfatória essas necessidades, e munidos do conhecimento adquirido dessas informações através do processo de apropriação, os sujeitos tendem a estabelecer uma relação consciente com o meio.

Segundo Oddone $(1998$, p. 2) “[...] estamos hoje absolutamente imbuídos da ideia de uma sociedade do conhecimento, globalizada, dependente do recurso estratégico informação". O advento da sociedade da informação, a que remontamos as transformações socioeconômicas e as composições das estruturas informacionais, trouxe consigo um misto de oportunidades e ansiedades, tanto em aspectos econômicos como em sociais.

Por outro lado, esta nova sociedade emergida das transformações e sustentada pelas tecnologias, delineia-se não só como uma sociedade de possibilidades, mas também de exclusões, já que ao mesmo tempo em que prega o acesso à informação como um direito que leva o cidadão a "[...] entender o crescimento do país em desenvolvimento", (CARVALHO, 
1991, p. 172), para exercício de sua cidadania, também o restringe em "[...] um sistema de desigualdade que se acentua e se agrava no sistema capitalista". (ROCHA, 2000, p.43).

Para Sanches e Almeida Júnior (2010, p. 1), “[...] no contexto atual a informação é considerada insumo básico necessário para o desenvolvimento de todos os segmentos da sociedade, seja ele científico, econômico ou político". Neste sentido, entendemos que neste cenário, marcado por "[...] uma sociedade informatizada, caracterizada por elevadas taxas de produção e de consumo de informação de vários tipos [...] e marcada por uma nova comunicabilidade e uma nova sociabilidade", que a informação adquiriu seu lugar de destaque. (ODDONE, 1998, p. 2).

Corroboramos com Castro (2000), ao afirmar que em meio todas as transformações ocorridas na sociedade contemporânea, a da noção de informação é a que se configura com maior impacto, já que não se estabelece limites para o seu poder de alcance. Destarte, a informação se caracteriza como um produto consumível que todos querem e merecem ter acesso, tendo "[...] influência decisiva no desenvolvimento de sujeitos atuantes na sociedade, bem como para o desenvolvimento de uma sociedade calcada no crescimento econômico político e científico [...]". (SANCHES E RIO, 2010, p. 105). Todavia, esse direito à informação, segundo Cavalcante (2012), trata-se de uma construção histórico-social e política, o que reflete diretamente na vida social e econômica das pessoas.

Segundo Farias (2014), o entendimento da relevância da informação e de se manter informado, já se faz presente na consciência de muitos indivíduos, o que reflete claramente em suas atitudes, uma vez que saem de suas zonas de conforto para reivindicar esse direito. Entendemos essa atitude como uma compreensão crítica dos seres humanos como protagonistas sociais, e assim como Freire (1978), destacamos ser esse o primeiro passo para o conscientização dos indivíduos, o qual se dá a partir da compreensão deste como um ser não só existente no mundo, mas como um ser atuante no mundo.

Uma vez consciente, o sujeito finalmente tem a possibilidade de se ver como um agente transformador, guiado por seus próprios objetivos, realizando “[...] a complexa operação de, simultaneamente, transformando o mundo através de sua ação, captar a realidade e expressá-la por meio de sua linguagem criadora", segundo Freire (1978, p. 65). A objetivação é outro ponto importante no processo de conscientização. Sem objetivos, os sujeitos estariam a esmo no mundo, pois não procurariam conhecê-lo nem conhecer a si mesmos, vivendo assim igual aos animais, que não estabelecem relações com o mundo e não refletem sobre suas vidas. Somos, como explica Almeida Júnior (2015), assim como as informações, [...] dependentes das relações que fazemos com o meio externo, que por sua vez nos levam ao entendimento, mesmo que inconscientemente do mundo. 
Assim como Freire (1978), outros autores, também destacam o indivíduo consciente como um ser aberto, sempre em busca de algo que o satisfaça. Rocha $(2000$, p. 43$)$ define conscientização como:

[...] um processo que permite o homem compreender a realidade que o cerca, como ela se estrutura, o que é e a reagir a essa realidade, assumindo seu destino e dos seus semelhantes com autonomia, buscando sempre melhores condições de vida.

Já dotado de consciência e imerso na realidade social, o homem busca formas de interagir com o meio, captando, refletindo e se expressando através da linguagem, um importante instrumento na formação de consciência, pois o conhecimento resulta do trabalho de interação entre o mundo e o sujeito em uma relação de dependência. Compreendemos a abordagem de Almeida Júnior (2015, p. 11), ao dizer que “[...] em suma, nosso conhecimento se constrói mediado e, da mesma forma, somos mediadores na construção do conhecimento dos outros".

Partindo deste pressuposto, defendemos com base em Farias (2014) o uso do processo de mediação para a transformação de realidades, por acreditar no potencial da informação em diminuir desigualdades. Como ressalta Targino (1991, p. 158), devemos colocar à disposição dos cidadãos, "[...] qualquer que seja sua escolaridade, informações que the propiciem ir à luta, em busca de seus direitos e compreensão de seus deveres". Acreditamos que a informação deve ser disseminada de forma democrática e em todos os aspectos, para que seu uso consciente seja transformado em conhecimento, derrubando barreiras que impossibilitam os sujeitos de estarem no mundo e dele participar, ou seja, sendo protagonistas de suas próprias vidas.

\section{Estratégias de mediação na biblioteca pública: para além do serviço de referência}

O processo de mediação da informação vai além de uma interação estabelecida entre a informação, o usuário e o bibliotecário, no momento de transferência da informação. A mediação da informação busca proporcionar aos envolvidos uma interação consigo mesmo, incentivando a atribuição de significados, mediante suas próprias interpretações. Esse processo geralmente está relacionado ao serviço de referência e informação da biblioteca, setor considerado por muitos o cerne de toda a prática bibliotecária.

Segundo Grogan (1995), o serviço de referência nasce com a justificativa de proporcionar os usuários um melhor aproveitamento do acervo da biblioteca, já que sem auxílio ficaria difícil utilizar as fontes de informação eficientemente. Buscava-se maximizar o compartilhamento dos registros com o intuito de beneficiar os indivíduos como um todo. 0 
fornecimento de informações através do serviço solicitado pelo usuário concretiza as ações de interação.

Apesar dessa relação entre o processo de mediação e o serviço de referência de informação, ou para melhor especificar, conforme Almeida Junior (2009, p. 92), "[...] aos espaços e ações que visam ao atendimento do usuário" é preciso entender que "a mediação pode ocorrer em qualquer espaço informacional e dentro desse espaço ela pode aparecer em cada segmento que o constitui", como explicam Almeida Júnior e Santos Neto (2014, p. 104). Isso permite afirmar que a mediação pode ou deveria estar presente em todas as ações desenvolvidas na biblioteca, desde o planejamento dos serviços, até o armazenamento e a disseminação das informações.

Partindo desse pressuposto, foi defendida a ideia de divisão da mediação da informação em duas dimensões: explícita e implícita. Essa divisão permitiria um melhor entendimento sobre o processo, sendo possível, como afirma Bortolin (2013), a desterritorialização da mediação da informação, tornando-a mais abrangente, além de possibilitar que todos os profissionais da biblioteca atuassem como mediadores.

A mediação explícita se refere às ações realizadas onde a presença dos usuários é indispensável, seja ela física ou não, como por exemplo, no serviço de referência. Compreendemos a mediação implícita pelo olhar de Almeida Júnior (2009, p. 92), que explica que:

\begin{abstract}
O armazenamento de informações é alimentado a partir de interesses e demandas dos usuários. A política de seleção, amplamente discutida no desenvolvimento de coleções, tem o usuário final como base de sustentação. O mesmo se dá com os trabalhos de processamento das informações: têm suas ações voltadas para a recuperação de informações que atendam e satisfaçam necessidades dos usuários.
\end{abstract}

Assim, de acordo com o autor, todas as atividades realizadas nos equipamentos informacionais norteiam e contribuem para o processo de mediação. É importante a compreensão por parte do profissional que atua nos setores da biblioteca, de que tanto a mediação explícita quanto a implícita, vão além da disponibilidade e do acesso aos materiais informacionais, ou seja, do conceito prático de mediação que é empregado em algumas instituições. Costa e Almeida Junior (2012) evidenciam que por tempos não houve preocupação em direcionar os serviços de informação aos usuários, e quando o interesse por estes enfim foi demonstrado, limitou-se apenas a supervalorização da organização para o uso, em linhas gerais, para a transferência de informação.

A mediação da informação surge da urgência de voltar os serviços da biblioteca não apenas para a oferta de materiais informacionais, mas também para sustentar o exercício dos 
profissionais nas duas ideias centrais da mediação da informação, interferência e apropriação. As duas ideias exigem, conforme Almeida Junior $(2015$, p. 19) "[...] um novo olhar sobre o fazer do profissional da informação, uma vez que não restringe o trabalho dele na entrega de materiais que atendam à necessidade informacional explicitada". A interferência se concretiza pela interação estabelecida entre os elementos da mediação, defendendo a ideia de construção de conhecimento por meio da relação coletiva. Por sua vez, a apropriação implica na compreensão do conteúdo veiculado no momento da mediação dependerá tanto do profissional, quanto do usuário. Nesta perspectiva, entendemos que a interação auxilia o processo de apropriação da informação.

Ainda de acordo com Almeida Junior (2015) para que haja mediação, é necessária a presença de um terceiro elemento. Esse terceiro elemento pode ser entendido como: o próprio profissional, as ações implementadas, o espaço de atuação e, por fim, os produtos documentários gerados por ele.

Tomando como exemplo o elemento ações implementadas, ressaltamos que são várias as possibilidades de mediação que podem ir desde o desenvolvimento de atividades recreativas como, oficinas, rodas de leitura, entre outros, até o planejamento de ações que possibilitem a interação entre o profissional e os envolvidos na ação. Todos os serviços devem ser pensados para e com o usuário, sempre levando em consideração que a BP, como instituição social, precisa manter-se atuante na sociedade, promovendo ações mediadoras que estimulem à participação e à aproximação.

\section{Abordagem metodológica}

Com a premissa de analisar as estratégias de mediação da informação utilizadas na Biblioteca Pública Municipal Capistrano de Abreu, e a postura dos profissionais diante do conhecimento e da importância do exercício da mediação, optamos pela abordagem qualitativa com o método de pesquisa de nível exploratória. A razão da escolha de caráter qualitativo se justifica pelo fato de a pesquisa qualitativa buscar uma compreensão da situação apresentada, além de estabelecer uma sintonia entre "[...] formas diferentes de consciência, sem tentar explicar como e porque elas se desenvolveram". (RICHARDSON, 2011, p. 91).

Acreditamos que tanto o processo de mediação da informação, quanto à abordagem qualitativa ocorrem por meio da interação social, nos levando assim a entender este nível de pesquisa. Na perspectiva de Strauss e Corbin (2008) entre tantas possibilidades, este tipo de abordagem pode também se referir a uma investigação sobre pessoas, e não de pessoas, assumindo assim uma característica social. Portanto, uma vez entrando em contato com sentimentos e necessidades dos sujeitos, atitude atualmente esperada dos bibliotecários e de 
profissionais da informação, esta aproximação facilita o processo de desenvolvimento de estratégias de mediação a serem empregadas na BPMCA, a fim de aperfeiçoar seus serviços e reestabelecer a relação entre biblioteca/usuário, além de auxiliar o processo de conscientização de sujeitos.

A pesquisa exploratória, por sua vez, de acordo com Richardson (1999), busca esclarecer conceitos e ideias, proporcionando uma visão geral acerca de determinado fato. Gil (1999, p. 43), enfatiza que este tipo de método de pesquisa tende a abrir espaços para novas ideias, na medida em que modifica conceitos, dando origem a novas problemáticas, que podem vir a ser aplicadas em estudos posteriores. "Este tipo de pesquisa é realizado especialmente quando o tema escolhido é pouco explorado, e torna-se difícil sobre ele formular hipóteses precisas [...]".

Assim como na pesquisa exploratória e na abordagem qualitativa, os resultados da mediação são totalmente relativos e interpretativos, equiparando-se a "[...] fenômenos como sentimentos, processos de pensamento e emoções que são difíceis de extrair ou descobrir por meio de métodos de pesquisa mais convencionais". (STRAUSS; CORBIN, 2008, p. 24). Acreditamos que trabalhar nesta perspectiva é explorar conhecimentos diversos por meio de visões diferentes, entender o significado de cada conceito levando em consideração a natureza e a experiência de cada um.

A coleta dos dados foi realizada pela técnica da observação participante, quando procedemos com anotações no diário de campo ao desenvolver atividades diárias no campo de pesquisa na função de estagiária. Caracterizamos a inclusão da observação participante a esta pesquisa, como um momento de conexão entre o pesquisador, o objeto e todos os outros elementos envolvidos, num exercício de captação profunda da realidade. Para Richardson (2011, p. 259), "[...] a observação é a base de toda a investigação no campo social [...]", estabelecendo uma forte contribuição no ato da investigação.

Também fizemos uso de um roteiro de entrevista e de questionário. 0 primeiro foi utilizado para coletar dados junto à bibliotecária e aos demais profissionais da BPMCA, a fim de garantir uma melhor análise acerca da percepção destes em relação à mediação da informação. Já o questionário foi aplicado aos usuários, buscando conhecer principalmente as necessidades informacionais dos participantes. Inferimos, assim como Gil (1999), que a entrevista não busca apenas a coleta de dados, mas também coloca o investigador em uma posição de orientador, à medida que facilita o envolvimento e o intercâmbio de ideias com o investigado. O critério de escolha dos entrevistados deu-se pela aproximação e interação dos profissionais diretamente com os usuários, uma escolha guiada pelas anotações no diário de 
campo durante a observação participante. O perfil desses profissionais é apresentado no Quadro 1:

Quadro 1 - Caracterização dos profissionais entrevistados na BPMCA

\begin{tabular}{|l|l|l|l|}
\hline \multicolumn{1}{|c|}{ Entrevistado } & \multicolumn{1}{|c|}{ Sexo } & \multicolumn{1}{c|}{ Profissão } & \multicolumn{1}{c|}{ Papel desempenhado na BPMCA } \\
\hline B1 & F & Bibliotecária & Gestão da BPMCA \\
\hline P1 & M & Professor & $\begin{array}{l}\text { Coordenador e professor do curso de } \\
\text { desenho }\end{array}$ \\
\hline P2 & F & Professora & $\begin{array}{l}\text { Responsável pelo atendimento no } \\
\text { acervo e coordenadora do setor de } \\
\text { literatura infantil. }\end{array}$ \\
\hline P3 & F & Auxiliar & $\begin{array}{l}\text { Responsável pelo atendimento no } \\
\text { Comitê para a Democratização da } \\
\text { informática (CDI) }\end{array}$ \\
\hline
\end{tabular}

Fonte: Dados da Pesquisa, 2016.

Dos onze profissionais que trabalham na BPMCA foram entrevistados apenas quatro, tendo em vista o critério descrito acima. Como se pode perceber, o quadro de funcionários da BPMCA é composto apenas por uma bibliotecária, sendo os demais funcionários divididos entre professores e auxiliares. A Biblioteca Pública Municipal Capistrano de Abreu como conhecemos hoje, teve sua inauguração em meados dos anos 2000, porém seu percurso histórico data desde 1940, quando ainda se chamava "Biblioteca 10 de Novembro", e não tinha localização fixa. Hoje, a BPMCA se encontra subordinada à Fundação Viva Maranguape de Turismo Esporte e Cultura (FITEC), e atualmente ocupa o Solar Bonifácio Câmara, prédio histórico da cidade. A unidade sem fins lucrativos tem suas ações voltadas para o público em geral, buscando proporcionar o acesso à informação, cultura, educação e lazer.

A biblioteca dispõe de um acervo de aproximadamente 15 mil exemplares, além de espaços destinados a exposições, pesquisa, e cursos extracurriculares. A BPMCA também é reconhecida como uma biblioteca polo da região metropolitana de Fortaleza, responsável pela divulgação de informações e conhecimentos para todas as bibliotecas localizadas em sua abrangência. A BPMCA é responsável pelo atendimento das bibliotecas de 25 municípios, localizados na região do Maciço de Baturité e Região Metropolitana de Fortaleza (RMF). Em relação aos serviços ofertados pela biblioteca, além de um espaço físico amplo para estudo, a BPMCA conta com: acervo literatura infanto-juvenil; acevo geral; acervo em braile; acervo de escritores regionais (e venda destes materiais); brinquedoteca; acervo de periódicos; espaço para eventos e reuniões; serviço de referência; sala de pesquisa com acesso a internet. Entre os projetos ofertados pela biblioteca, destacamos: oficinas de literatura infantil com a 
colaboração das escolas da região; semana da literatura infantil; projeto leitura e arte; Comitê para a Democratização da informática (CDI).

Para analisar os dados coletados utilizamos a técnica análise de conteúdo com o estabelecimento de categorias. Segundo Richardson (2011), a análise de conteúdo é empregada na abordagem qualitativa, e busca não somente a análise rigorosa do que é demonstrado na mensagem, mas também o que está implícito nela. Assim, a análise de conteúdo estimula e exige do pesquisador uma exploração mais exaustiva do material, favorecendo consequentemente, ao aumento do nível de interpretação.

Em relação à categorização, a escolha se deu pelo fato desta está diretamente ligada à técnica de análise de conteúdo, além de permitir uma melhor distribuição dos dados, uma vez que podemos reagrupá-los de acordo com suas especificidades. As categorias estabelecidas foram: a) Necessidades informacionais dos usuários: esta categoria visou conhecer os assuntos e informações que mais interessam os usuários da BPMCA, e onde eles costumam buscar essas informações. Também associamos a esta categoria a interação entre a BPMCA e seus usuários, analisando suas opiniões em relação aos serviços e profissionais da biblioteca; b) Compreensão do conceito de mediação: apresenta a compreensão do conceito e do processo de mediação dos profissionais que atuam diretamente com o usuário na BPMCA; c) Competência em informação para mediação: esta categoria buscou a partir da compreensão do processo de mediação da informação, verificar a competência dos profissionais da biblioteca na realização das ações; d) Estratégias de aproximação e mediação: analisamos as ações realizadas na BPMCA, que possibilitam a interação e a aproximação dos usuários, a fim de mostrar como a biblioteca atua em prol da construção da informação.

A categoria, necessidades informacionais dos usuários, foi analisada a partir dos dados coletados somente nos questionários aplicados aos usuários. As categorias, compreensão do conceito de mediação, competência em informação para mediação, e estratégias de aproximação e mediação foram analisadas a partir dos dados coletados no momento da entrevista com os profissionais da BPMCA.

\section{Análise e discussão dos dados}

Para figurar nesta comunicação escolhemos duas categorias de análise: Necessidades informacionais dos usuários e Estratégias de aproximação e mediação. A primeira objetivou conhecer e analisar a necessidades informacionais dos usuários, pois, de acordo com Almeida Júnior (2009), todos os serviços ofertados pela biblioteca, devem ter como base de sustentação o usuário e o atendimento de suas necessidades, caso o contrário os serviços não teriam razão de ser. Além disso, ainda segundo o autor, a mediação está presente em todos os 
momentos, e a biblioteca trabalha para mediar a informação para satisfazer as necessidades informacionais de seus usuários.

As necessidades informacionais dos indivíduos podem ser desencadeadas por diversos fatores. Na visão de Silva (2012, p. 105), “[...] as necessidades de informação são frutos de fenômenos sociais de interação com outros seres, que estimulam a consciência para a construção de informação". Assim, nos convêm afirmar que o conhecimento das necessidades informacionais dos usuários da BPMCA, favoreceram as sugestões de ações empregadas na unidade, que atinjam todos os envolvidos no processo mediação da informação.

As questões desta categoria objetivaram investigar os principais meios de busca de informação utilitária pelos usuários, no sentido de analisar se a BPMCA é vista como um centro de informação para a comunidade, como mostra o Gráfico 1.

\section{Gráfico 1 - Meios de busca da informação}

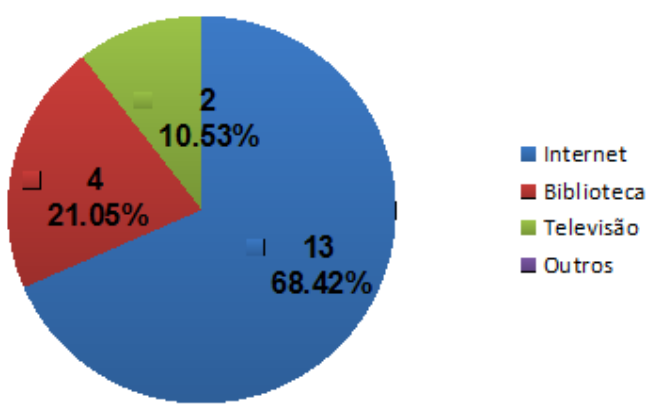

Fonte: Dados da pesquisa, 2016.

Como se pode observar, a internet foi a mais citada, obtendo 68 pontos percentuais na pesquisa. Esse dado confirma que para os usuários, a internet se configura como uma das melhores formas de se atualizar e se obter informação em meio cenário em que estamos inseridos. A biblioteca foi a segunda mais citada, sendo mencionada quatro vezes, totalizando $21 \%$. Esse fato nos permite afirmar que há falta de hábito, ou até mesmo a falta de conhecimento da parte dos usuários de que a biblioteca, como afirma Almeida Júnior (1997, p. 75), “[...] não trabalha exclusivamente com livros [...] a essência do trabalho da biblioteca é a informação".

Porém, cabe ressaltar que como os entrevistados podiam escolher mais de uma opção de resposta em cada pergunta, os que citaram a biblioteca como meio de se obter informação, citaram juntamente a internet, o que nos faz inferir, por meio de nossas observações, que estes se utilizam do serviço de acesso grátis à internet da BPMCA. A televisão vem em terceiro lugar, com um total de $11 \%$. Este foi um dado que nos chamou atenção, pois sabemos que este 
é um dos veículos de informação mais frequentes no cotidiano da população. A opção outros não foi citada em nenhum momento.

Os usuários da BPMCA também foram questionados quanto aos assuntos ou informações que costumam procurar na biblioteca. A pergunta foi elaborada com o intuito de descobrir o que motiva os usuários a procurarem a BPMCA. (Gráfico 2).

\section{Gráfico 2 - Assuntos ou informações procuradas na BPMCA}

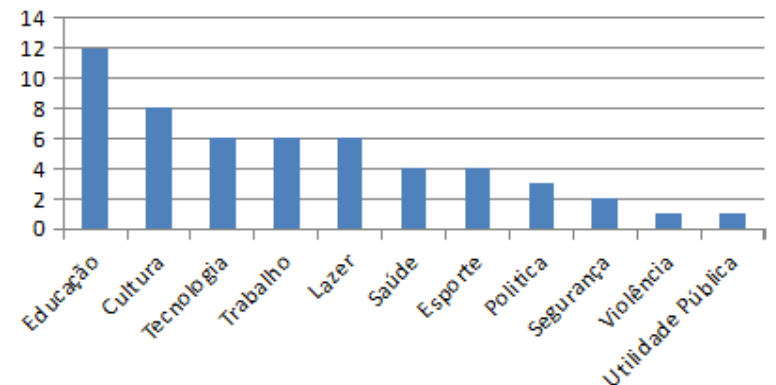

Fonte: Dados da pesquisa, 2016.

Os assuntos ou informações procurados na BPMCA são variados. Para que pudéssemos ter uma base das preferências dos usuários, cada participante teve a oportunidade de marcar mais de um assunto. Os assuntos mais procurados foram educação e cultura, mencionados doze e oito vezes. Para o item educação, acreditamos, por meio de nossa observação e de informações coletadas, que a grande demanda ocorre pelo fato de a biblioteca trabalhar também com a colaboração das escolas da região, isto por que, as escolas do município não têm de biblioteca escolar para atender os alunos, cabendo assim à biblioteca pública atender as necessidades dos estudantes e professores.

Os itens tecnologia, trabalho e lazer foram citados de forma unânime pelos usuários. 0 que mais nos chamou atenção foram os itens utilidade pública e violência, mencionados apenas uma vez. Essa observação vai ao encontro da pergunta anterior, onde ressaltamos que a biblioteca ainda é vista por poucos como um centro de informação pública.

Em relação aos serviços oferecidos pela BPMCA, perguntamos aos usuários quais eles costumavam utilizar. Todos os serviços ofertados foram disponibilizados, e mais uma vez, houve a possibilidade de se citar mais de um item. O resultado foi que a pesquisa feita pela internet obteve o maior número de respostas, seguidos pelo serviço de empréstimo, participação em cursos e oficinas e o uso do espaço físico da biblioteca para estudo.

Novamente os usuários confirmam o uso da internet como um dos meios mais utilizados para se obter informação rapidamente. Cabe ressaltar que a maioria dessas pesquisas também está relacionada a conteúdos de cunho educativo, reforçando ainda mais o estereótipo da biblioteca pública como uma extensão da biblioteca escolar. Não que isso seja 
um problema, afinal sabemos que em meio às várias funções da BP, a educacional é uma de suas bases de sustentação, contudo, concordamos com Machado; Elias Júnior e Achilles (2014) ao afirmar que é preciso começar a visualizar a biblioteca pública dentro do contexto da sociedade e desenvolver estratégias que mobilizem a comunidade, promovendo seu reconhecimento como espaço público.

Quando questionados sobre que materiais informacionais gostariam de encontrar na BPMCA, 100\% dos entrevistados demonstraram interesse por um acervo mais diversificado e atual. Os assuntos mais citados foram: livros de literatura (Best Sellers); materiais relacionados à música e teatro; periódicos, monografias e teses com temas atuais; e materiais destinados a concurso. Quanto aos serviços, obtivemos os seguintes resultados: $43 \%$ dos usuários desejam espaços mais interativos e ações voltadas que promovam um contato direto com a comunidade atingindo faixas etárias variadas, com atividades que envolvam jogos (RPG), desenhos e palestras de orientação; 36\% gostariam de encontrar na BPMCA cursos e oficinas voltadas educação; por fim, $21 \%$ sugeriram serviços e eventos culturais e de lazer como musica e teatro.

Ainda nesta categoria, acrescentamos perguntas relacionadas ao comportamento do usuário diante da necessidade de ir ao encontro da informação e se eles conseguem se orientar dentro do acervo da biblioteca sem auxílio de um profissional. Estas perguntas foram necessárias para analisarmos como se dá a interação entre usuários e profissionais atuantes

Gráfico 3 - Localização de material informacional

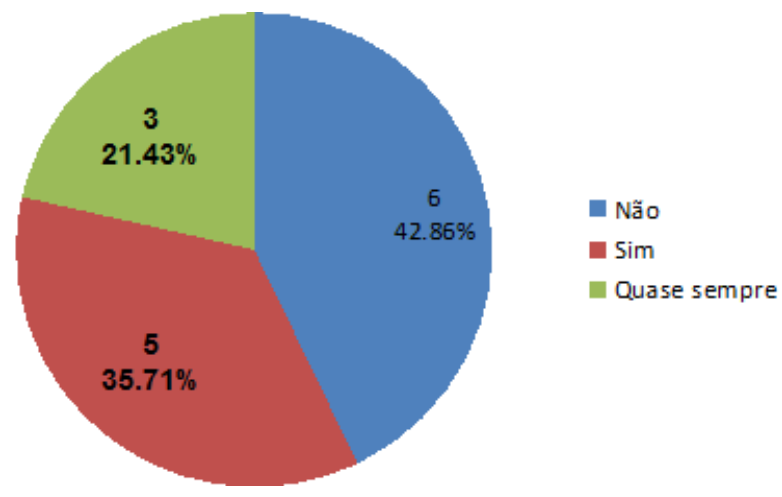

Fonte: Dados da pesquisa, 2016.

Dos 14 participantes da pesquisa, 43\% responderam que não encontram sozinhos e sempre pedem ajuda a algum profissional da biblioteca. Por meio de nossas observações, acreditamos que isso pode ocorrer por dois motivos, quais sejam: a) o acervo da biblioteca se encontra disperso, distribuído em várias salas que compreendem o térreo e o primeiro andar, e não há placas de orientação que chamem atenção do usuário; b) apesar da disponibilidade 
de computadores para pesquisa, os usuários não têm acesso ao sistema automatizado (BibLivre), sendo este exclusivo para uso dos profissionais da BPMCA. Quando o material solicitado não é encontrado no sistema, o assunto é dado como não existente no acervo.

Quanto aos 36\% que afirmaram encontrar sozinhos o que procuram, alguns complementaram dizendo que pesquisam apenas no computador pessoal. Assim, visualizamos que estes nem sempre fazem uso do acervo, mas frequentam a BPMCA para uso de seu espaço físico e de sua rede de internet. Por fim, $21 \%$ responderam que quase sempre encontram o que precisam, porém na dúvida não descartam o auxílio.

Em relação ao questionamento da interferência do profissional na busca pela informação, os $43 \%$ que relataram não encontrar a informação, destacam o empenho do profissional na busca pela informação solicitada. Todavia, quando o que é desejado não existe ou não está disponível no acervo, a orientação é que se faça a busca em meio eletrônico. Daí a pesquisa é realizada de forma livre.

Para concluir, procuramos descobrir como estava o grau de satisfação dos usuários em relação à BPMCA e aos serviços ofertados. Diante das limitações e de algumas insatisfações, apenas $21 \%$ consideraram os serviços excelentes, ficando o grau de satisfação entre bom (50\%) e regular (29\%). O Gráfico 4 mostra o grau de satisfação dos usuários em relação aos serviços:

Gráfico 4 - Grau de satisfação dos usuários com relação aos serviços da BPMCA

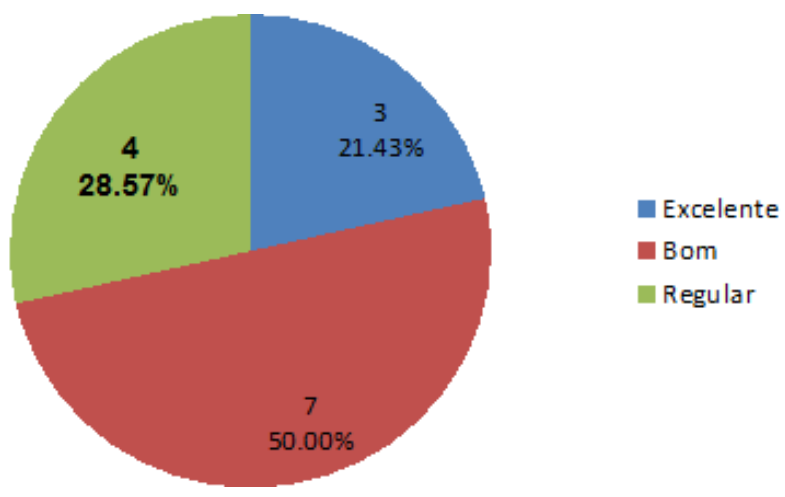

Fonte: Dados da pesquisa, 2016.

Diante de todos os questionamentos relacionados à categoria necessidades informacionais dos usuários, nota-se que ainda falta por parte da BPMCA, um maior posicionamento no que se refere à disseminação e mediação da informação voltada para as necessidades dos seus usuários. Como foi visto, não só o acervo, mas também as outras atividades, não correspondem às expectativas dos usuários, uma vez que não conseguem 
compreender o espaço da BPMCA como um lugar de interação social, associando-lhe apenas a uma instituição de utilidade provisória, enquanto ainda são estudantes.

A categoria estratégias de aproximação e mediação objetiva analisar as ações realizadas na BPMCA, que possibilitam a interação e a aproximação com os usuários, a fim de demonstrar como a biblioteca atua em prol da construção de conhecimentos.

Face ao exposto, para analisarmos se as ações empreendidas na BPMCA estão alicerçadas nos pressupostos da mediação da informação, tomamos por base as indagações de Almeida Junior (2014), ao afirmar que para que haja mediação da informação é imprescindível a presença de um terceiro elemento constituído por quatro itens: profissional, ações implementadas, espaço de atuação e produtos documentários gerados por ele. Utilizamos aqui os três últimos itens, visto que o elemento profissional já fez parte da categoria acima.

Para o elemento, espaço de atuação, uma das estratégias de aproximação citada pelos entrevistados foi a divulgação dos serviços da biblioteca para os usuários. Segundo P1 essa divulgação acontece no momento em que os profissionais buscam informar os usuários "sobre tudo o que é ofertado pela biblioteca, tanto pelos avisos colocados nas dependências do prédio quanto nas oportunidades de interação com eles". Para B1 através dessa comunicação "os usuários saberão como a biblioteca é viva e ativa diante da comunidade".

Podemos verificar que as respostas de P1 e B1, se assemelham, pois ambos buscam criar estratégias para a difusão dos serviços ofertados pela biblioteca. Essa divulgação sinaliza a preocupação desses profissionais para e com o usuário, buscando aproximação através de serviços de interesses mútuos.

No que se refere às ações implementadas consideramos as seguintes respostas: "Ofertamos oficinas, encontros da melhor idade, encontros de RPG, debates com artistas no curso de desenho" (P2). "Realizamos oficinas e cursos voltados para as escolas e comunidade como um todo" (P1).

Uma das sugestões de serviços mais citadas pelos usuários da BPMCA, foi exatamente a realização de oficinas que atingissem todos os públicos, o que se contrapõe ao que disse P1 e P2, pois afirmam que há a realização dessas ações. Porém, ao nos reportarmos a fala de P1, notamos que foi dito que essas ações também são voltadas para a escola. Assim, por meio de nossas observações, inferimos que na verdade há a falta de conhecimento por parte dos usuários sobre a realização das oficinas, visto que essas, na maioria das vezes já prédeterminam seu público-alvo. Possivelmente ocorre falta de comunicação entre a biblioteca e os usuários quanto às oficinas, ou não estão considerando as necessidades de informação destes para essa atividade em específico. 
Analisando o último item, produtos documentários gerados pelo profissional, indagamos aos entrevistados como ocorre a participação do usuário para composição do acervo. Acreditamos que esse questionamento se enquadra nesse item, a partir do momento em que o profissional é responsável pela produção de produtos documentários que envolvam o usuário satisfatoriamente. Obtivemos as seguintes respostas: "Recebemos sugestões, as quais são armazenadas e sugeridas em reuniões, além disso, aplicamos questionários para descobrir o perfil de nossos usuários" (B1). "Por meio de conversas, onde os mesmos são motivados a fazer suas sugestões" (P2). "Procuramos conhecer as necessidades dos frequentadores da biblioteca, tanto de forma perceptiva, como percentual, por meio de levantamento e relatórios mensais" (P3). Essas respostas se contrapõem aos dados obtidos junto aos usuários, os quais responderam no questionário que vários materiais informacionais que buscam, não são encontrados na biblioteca, o que nos leva a perceber que mesmo buscando a opinião dos usuários para compor o acervo, a biblioteca ainda não consegue atender com excelência seus usuários. Todavia, é preciso ressaltar que a BPMCA não conta com orçamento próprio para compra de materiais, sendo seu acervo constituído por meio de doações.

Dessa maneira, aferimos que existem tanto estratégias de aproximação na BPMCA, quanto ações que são realizadas nas dependências da biblioteca, as quais condizem com os pressupostos da mediação da informação, uma vez que há o terceiro elemento exigido para sua concepção. Porém, é pertinente ressaltar que ainda há limitações que dificultam o processo de mediação que evidenciamos nesta pesquisa, como, por exemplo, uma carência de interação no momento da interferência. Cabe ao mediador a preocupação com o modo de interferir, já que isto é imprescindível para reconhecimento dos interesses informacionais dos usuários.

\section{Considerações finais}

A sociedade da informação imprimiu mudanças no cenário social, modificando as relações humanas em vários aspectos. A busca pela informação se intensificou e diversificou os ciclos informacionais, favorecendo a interação social, e potencializando o processo de construção de conhecimentos. O processo de mediação se insere nesses espaços informacionais, e se relaciona com a construção de sentidos, uma vez que se expressa por meio da ação de interferência, na intenção de nortear a busca pelo conhecimento.

Consideramos a mediação da informação uma relação estabelecida entre os envolvidos no momento da disseminação da informação, capaz de modificar percepções e promover o crescimento e o conhecimento mútuo. Diante desse contexto, e considerando que 
o acesso à informação na contemporaneidade se configura como o elemento básico para a construção de sentidos, refletimos acerca do papel desempenhado pela biblioteca pública como uma instituição social, e a importância da qualificação do profissional atuante na referida biblioteca para desempenhar o papel de mediador, desenvolvendo habilidades e competências, para promover ações de mediação que visem à apropriação da informação, e por consequência, a conscientização.

Acreditamos que para propor estratégias de mediação a serem empregadas na unidade, devemos primeiramente conhecer o público que ela atende, pois seus serviços devem ser planejados para e com os usuários, caso contrário a mediação não provocaria as mudanças almejadas, uma vez que a informação mediada não promoveria o encontro do sujeito com sua "prontoinformação" e não atenderia suas necessidades informacionais.

Após essa análise, consideramos que há uma breve insatisfação por parte dos usuários, tanto em relação aos materiais informacionais, quanto aos serviços oferecidos pela unidade. Outro ponto importante destacado foi a visão dos usuários em relação à BPMCA. Para eles, esta biblioteca se resume apenas a um espaço destinado ao estudo. Posto isso, inferimos as seguintes considerações:

- os profissionais da BPMCA compreendem o processo de mediação da informação relacionado apenas aos serviços oferecidos pela biblioteca (aqueles onde a presença do usuário é indispensável);

- há no ambiente da biblioteca a realização de ações de mediação que possibilitam o desenvolvimento de competências para todos os envolvidos, uma vez que a mediação da informação interfere tanto na aprendizagem dos usuários quanto do mediador. Porém, observamos que falta da parte dos profissionais da biblioteca um maior posicionamento na realização dessas ações;

- segundo os profissionais entrevistados as estratégias de aproximação e mediação ocorrem por meio da interação estabelecida entre: usuários, profissionais e biblioteca, quando os usuários são motivados a participar do planejamento dos serviços oferecidos.

Nesta perspectiva, concluímos que predomina na BPMCA a mediação da informação em sua forma implícita, destacando que os serviços oferecidos pela unidade são em sua maioria as atividades meio, ou aquelas que são planejadas e executadas sem a presença obrigatória dos usuários, e que servem de base para todas as outras atividades. Não queremos dizer com isso que não há mediação explícita, como foi afirmado e compreendido pelos profissionais, mas por meio de nossas observações, entendemos que há uma preocupação maior com o planejamento das ações. Sabemos que é na execução dessas ações que se estabelecem as interações.

Levando em consideração a fala dos usuários em relação aos materiais informacionais disponibilizados na BPMCA, percebemos que há empecilhos que dificultam a concretização da 
mediação da informação, já que esta visa acima de tudo à apropriação da informação por meio da satisfação das necessidades informacionais dos sujeitos. Se o acervo da unidade não corresponde ao procurado pelos usuários, eles não se apropriaram das informações contidas no lugar.

Aproveitando o desejo dos usuários por materiais informacionais relacionados à educação, e tendo em vista que o acervo deixa a desejar nesse ponto, sugerimos que a biblioteca faça uso dos seus espaços para promover cursos ou disponibilizar esse espaço para realização dos mesmos. Constatamos que há uma grande demanda quanto à realização de eventos dentro da biblioteca.

Por se tratar de uma biblioteca pública, ela precisa estar de portas abertas para a comunidade. Posto isso, observamos que os eventos e alguns cursos realizados nas dependências da BPMCA, não são propriamente promovidos por ela, mas por terceiros que se interessam pelo espaço. Essas ações de terceiros não são divulgadas pela biblioteca, a não ser que seja um evento aberto ao público.

Ao final, sugerimos que a biblioteca mantenha o foco em planejar e realizar ações de mediação que favoreçam a apropriação da informação por meio de intervenções sociais, como ações culturais, mediações orais e de leitura, oficinas entre outros. Além de atender aos anseios dos usuários, que deixaram claro o interesse por essas manifestações, a BPMCA também estará abrindo suas portas para a comunidade, posicionando-se e mobilizando-se frente à sociedade, à medida que presta serviços de informação para a população local. Esses eventos tendem a instigar a participação coletiva, onde experiências são compartilhadas e conhecimentos são construídos.

\section{Referências}

ALMEIDA, Marco Antônio de. Mediação cultural e da informação: considerações socioculturais e políticas em torno de um conceito. In: ENANCIB, 8., 2007, Salvador, BA. Anais... Salvador, BA: Universidade Federal da Bahia, 2007. p. 1-6.

ALMEIDA JUNIOR, Oswaldo Francisco de. Biblioteca pública e comunidade: um vínculo ainda inexistente. In: ALMEIDA JUNIOR, Oswaldo Francisco de. Sociedade e Biblioteconomia. São Paulo: Polis, 1997. p. 74-82.

ALMEIDA JUNIOR, Oswaldo Francisco de. Mediação da informação: um conceito atualizado. In: BORTOLIN, Sueli; SANTOS NETO, João Arlindo dos; SILVA, Rovilson Jose da (Org.). Mediação oral da informação e da leitura. Londrina: Abecin, 2015. p. 9-32.

ALMEIDA JÚNIOR, Oswaldo Francisco de; SANTOS NETO, João Arlindo dos. Mediação da informação e a Organização do Conhecimento: interrelações. Informação \& Informação, Londrina, v. 19, n. 2, p. 98-116, 28 abr. 2014.

ALMEIDA JÚNIOR, Oswaldo Francisco. Mediação da informação e múltiplas linguagens. Pesquisa Brasileira em Ciência da Informação, Brasília, v. 2, n. 1, p. 89-103, jan./dez. 2009. 
BARDIN, L. Análise de conteúdo. Lisboa: Edições 70, LDA, 2009.

BORTOLIN, Sueli. Mediação da informação: outras definições. 2013. Disponível em: <http://www.ofaj.com.br/colunas_conteudo_print.php?cod=785>. Acesso em: 06 out. 2016.

BORTOLIN, Sueli; SANTOS NETO, João Arlindo dos. Mediação oral da informação: a visibilidade dos mediadores da Ciência da Informação. In: BORTOLIN, Sueli; Rovilson José da (Org.). Mediação oral da informação e da leitura. Londrina: Abecin, 2015. Cap. 2. p. 33-58.

BUSQUET, Leandro Martins Cota. Bibliotecas Universitárias e o impacto das políticas públicas do ensino superior: o caso da BCG/UFF. 2012. 167 f. Dissertação (Mestrado em Ciência da Informação)- PPGCI/Universidade Federal Fluminense, Niterói, 2012.

CARDOSO, Gustavo Leitão. A mídia na sociedade em rede: filtros, vitrines, noticias. Rio de Janeiro: Editora FGV, 2007.

CARVALHO, Kátia de. Informação: direito do cidadão. In: CONGRESSO BRASILEIRO DE BIBLIOTECONOMIA E DOCUMENTAÇÃO, 16, Salvador, 1991. Anais... Salvador: APBEB, 1991. V. 2, p. $1172-1180$.

CASTRO, César Augusto. Profissional da informação: perfis e atitudes desejadas. Informação \& Sociedade: Estudos, João Pessoa, v. 10, n. 1, 2000. Disponível em:

<http://periodicos.ufpb.br/ojs/index.php/ies/article/view/346/268>. Acesso em jul. 2015.

CAVALCANTE, Lidia Eugênia. Mediação da informação, desenvolvimento local e comunidades. In: CASTRO, César Augusto; PINTO, Virginia Bentes; VIDOTTI, Silvana Aparecida Borsetti Gregório (Org.). Ciência da Informação e contemporaneidade: tessituras e olhares. Fortaleza: UFC, 2012. Cap. 2. p. 117-133.

COELHO NETTO, João Teixeira. Semiótica, informação e comunicação: diagrama da teoria do signo. 5. ed. São Paulo: Perspectiva, 2001. 217 p

COSTA, Maria de Fátima Oliveira Costa; ALMEIDA JÚNIOR, Oswaldo Francisco de. Os conceitos de estudos de usuários e a visão do bibliotecário no processo de mediação da informação. In: CAVALCANTE, Lidia Eugênia; PINTO, Virginia Bentes; VIDOTTI, Silvana Aparecida Borsetti Gregório (Org.). Ciência da Informação e contemporaneidade: tessituras e olhares. Fortaleza: UFC, 2012. Cap. 2. p. 59-87.

DAVALLON, Jean. A mediação: a comunidade em processo? Prisma .com: Revista de Ciências e Tecnologias de Informação e Comunicação do CETAC. MEDIA, Porto, n.4, 2007. Disponível em: <http://revistas.ua.pt/index.php/prismacom/article/view/645/pdf>. Acesso em: 29 nov. 2015.

FARIAS, Maria Giovanna Guedes Análise da produção, implementação e avaliação de um modelo de mediação da informação no contexto de uma comunidade urbana. 2014. 282 f. Tese (Doutorado) - Curso de Ciência da Informação, Universidade Federal da Bahia, Salvador, 2014. Disponível em

$<$ https://repositorio.ufba.br/ri/bitstream/ri/16851/1/Tese-Maria Giovanna Guedes Farias.pdf>. Acesso em: 28 nov. 2015.

FREIRE, Paulo. Ação cultural para a liberdade: e outros escritos. 3.ed. Rio de Janeiro: Paz e Terra, 1978.

GIL, Antonio Carlos. Métodos e técnicas de pesquisa social. 5. ed. São Paulo: Atlas, 1999.

GROGAN, Denis Joseph. A prática do serviço de referência. Brasília: Briquet de Lemos/ Livros, 1995.

MACHADO, Elisa Campos; ELIAS JUNIOR, Alberto Calil; ACHILLES, Daniele. A biblioteca pública no espaço público: estratégia de mobilização cultural e atuação sócio-política do bibliotecário. Perspectivas em Ciência da Informação, Belo Horizonte, v. 14, número especial, p.115-127, out./dez. 2014. 
MARQUES, Mário Osório. A aprendizagem na mediação social do aprendido do aprendido e da docência. 3. ed. ljuí, RS: Ed. Unijuí, 2006. 4 v.

MCGARRY, Kevin. O contexto dinâmico da informação: uma análise introdutória. Brasília: Briquet de Lemos, 1999.

ODDONE, Nanci. O profissional da informação e a mediação de processos cognitivos: a nova face de um antigo personagem. Informação \& Sociedade: estudos, João Pessoa, v. 8, n. 1, 1998. Disponível em: <http://www.ies.ufpb.br/ojs/index.php/ies/article/view/425>. Acesso em: 26 nov. 2015.

RICHARDSON, Roberto Jerry. Pesquisa social: métodos e técnicas. 3. ed. São Paulo: Atlas, 2011.

ROCHA, Marisa Perrone Campos. A questão cidadania na sociedade da informação. Ciência da Informação, Brasília, v. 29, n. 1, p. 40-45, jan./abr. 2000.

SANCHES, Gisele A. Ribeiro; RIO, Sinomar Ferreira do. Mediação da informação no fazer do bibliotecário e seu processo em bibliotecas universitárias no âmbito das ações culturais. InCID: Revista de Ciência da Informação e Documentação, Ribeirão Preto, v. 1, n. 2, p. 103-121, jul./ dez. 2010. Disponível em:<http://www.revistas.usp.br/incid/article/view/42323/45994>. Acesso em abril de 2016.

SANCHES, Gisele Ap. Ribeiro; ALMEIDA JÚNIOR, Oswaldo Francisco de. Mediação da Informação e teorias pedagógicas: um estudo acerca das contribuições no fazer do bibliotecário mediador. Disponível em:

<http://www.sibi.ufrj.br/snbu2010/pdfs/orais/final_021.pdf> .Acesso em 15 de nov. de 2015.

SANTAELLA, Lúcia; NOTH, Winfried. Comunicação e semiótica. São Paulo: Hacker Editores, 2004.

SIGNATES, Luiz. Estudo sobre o conceito de mediação. Revista Novos Olhares. ECA/ USP, v. 1, n. 2, p. 37- 49, 1998.

SILVA, Jonathas Luiz Carvalho. Necessidades de informação e satisfação do usuário: algumas considerações no âmbito dos usuários da informação. InCID: Revista de Ciência da Informação e Documentação, Ribeirão Preto, v. 3, n. 2, p. 102-123, jul./dez. 2012. Disponível em: <http://www.revistas.usp.br/incid/article/view/48656/52727>. Acesso em: 12 out. 2016.

SILVA, E. L. C.; LOPES, M. I. A internet, a mediação e a desintermediação da informação. DataGramaZero, Rio de Janeiro, v. 12, n. 2, p. 0-0, 2011. Disponível em: <http://basessibi.c3sl.ufpr.br/brapci/v/a/10071>. Acesso em: 2 fev. 2017.

STRAUSS, Anselm; CORBIN, Juliet. Pesquisa qualitativa: técnicas e procedimentos para o desenvolvimento de teoria fundamentada. 2. ed. Porto Alegre: Artmed, 2008.

TARGINO, Maria das Graças. Biblioteconomia, Informação e Cidadania. Revista da Escola de Biblioteconomia da UFMG, Belo Horizonte, v. 20, n. 2, p. 149-160, jul./dez. 1991.

TOALDO, Adriane Medianeira. Mediação de conflitos: alternativa à jurisdição na concretização dos direitos fundamentais sociais. Âmbito jurídico, Rio Grande , v. 14, n. 92, set. 2011.

Disponível em: <http://www.ambito-

juridico.com.br/site/index.php?n_link=revista_artigos_leitura\&artigo_id=10175>. Acesso em dez. 2015. 